\title{
Movement in Maxillary Third Molar Resulting in Open Proximal Contact Between First \& Second Molar: A Case report
}

\author{
Aiman Sheikh ${ }^{1}$ \\ Farhan Raza Khan ${ }^{2}$
}

BDS

BDS, MS, PhD, MCPS, FCPS

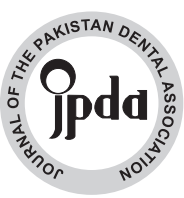

\begin{abstract}
Proximal contact area is the part of the tooth which touches the adjacent tooth in the same arch. Untreated open proximal contact between posterior teeth is very cumbersome for the patient as it allows food stagnation between teeth leading to caries and crestal bone loss. Dental caries and periodontal disease are the common cause of open contacts between posterior teeth. This report demonstrates an unusual cause of bilateral open proximal contacts i.e. movement in the maxillary third molars. Third molars sometimes exert unwanted force at the radicular part of the adjacent second molars which result in an orthodontic tipping movement of the second molar in the distal direction. This leads to creation of an open contact distal to the first molar. The present case was managed with the extraction of the third molars followed by direct amalgam restorations in the first and second molars. At one-year follow up, the patient remained asymptomatic. KEY WORDS: Proximal contacts; tooth movement: impacted teeth

HOW TO CITE: Sheikh A, Khan FR. Movement in maxillary third molar resulting in open proximal contact between first \& second molar: a case report. J Pak Dent Assoc 2018;27(1):43-45.

DOI: https://doi.org/10.25301/JPDA.271.43

Received: 17 December 2017, Accepted: 17 January 2018
\end{abstract}

\section{INTRODUCTION}

$\mathrm{P}$ roximal contact area is the part of the tooth which touches the adjacent tooth in the same arch. ${ }^{1}$ Their function is to maintain normal mesio-distal relationship of teeth and to preserve the stability and integrity of the dental arch. An anatomically correct proximal contact allows normal healthy interdental papilla to fill in the interdental space, protects the interproximal tissues from periodontal disease and prevents food impaction. ${ }^{2,3}$

An open proximal contact is a condition where adjacent teeth fail to make correct contact with each other. It may be due to a non-ideal occlusion, tooth loss, faulty restoration, drifting of teeth, oral diseases or oral habits. An untreated open contact area initially causes discomfort due to impaction of food and accumulation of bacterial plaque and eventually leads to proximal caries (class II carious lesions on proximal surfaces) and periodontal disease resulting from interdental crestal bone loss. Therefore, reproduction of the contact size and location of the contact area to imitate the natural dentition is essential for the success of the operative dental procedure. Proximal restorations that have correct anatomy, contour, location and configuration are imperative to maintain the

1. Karachi Medical \& Dental College, Karachi, Pakistan.

2. Associate Professor \& Head of Dental Section, Aga Khan University Hospital, Karachi, Pakistan.

Corresponding author: "Dr. Farhan Raza Khan" < farhan.raza@aku.edu > adjacent soft tissues from future insults. Inability of dentist to develop the physiologic contact area and contours in the proximal restorations results in the failure of restorative work. ${ }^{4}$

Third molar is the most commonly impacted tooth in the human dentition. Completely Impacted or partially impacted third molar can result in pain, damage to the other teeth, malocclusion. ${ }^{5}$ But in the present case, third molars have resulted in the tipping movement of the adjacent second molar, creating an open proximal contact between first and second molars.

\section{CASE REPORT}

A 30 year-old male presented for consultation at the Operative Dentistry clinic of the Aga Khan University Hospital, Karachi in 2016 with the chief complaint of bilateral food impaction between maxillary first and second molars (figure $1 \mathrm{a}$ and $\mathrm{b}$ ). The patient's medical history was noncontributory. Clinical examination revealed bilateral open proximal contacts between first and second molars but no caries. On probing with a University of Michigan graduated periodontal probe (Williams's probe), the probing depth for both teeth was within normal limits. The peri-apical radiographs were taken which revealed erupted maxillary third molars. Panoramic radiograph was then offered which showed that the crowns of both partially impacted maxillary third molars were pressing on the second molars and causing 

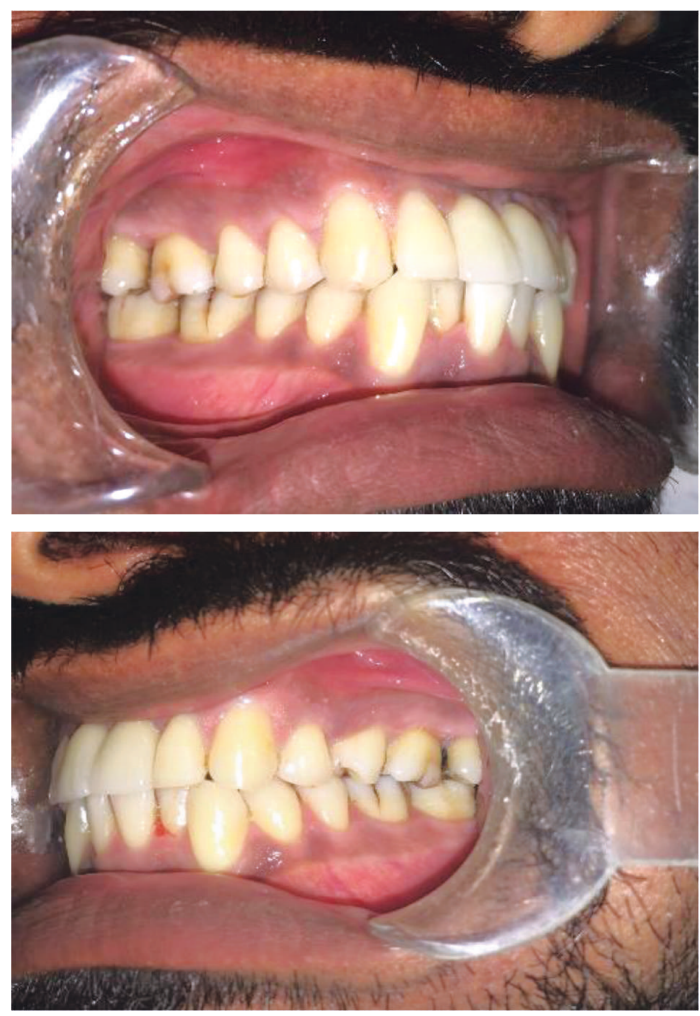

Fig 1a \& b. Pre-operative Intra-oral photograph of right and left sides

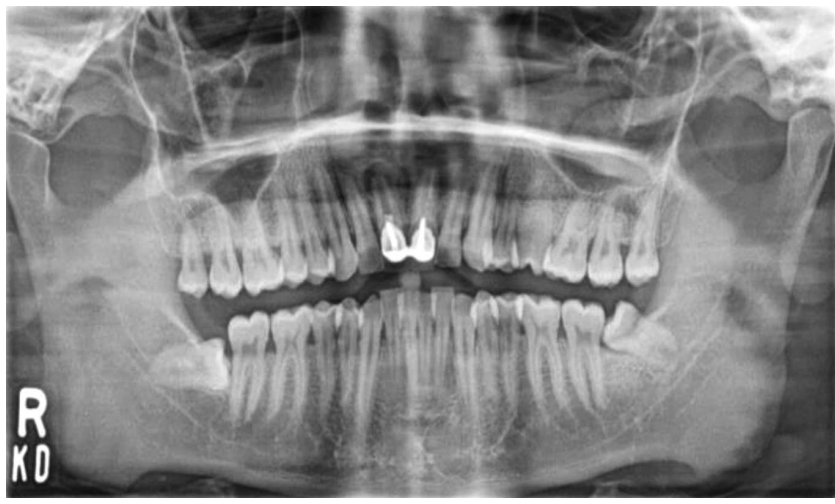

Fig 2. Pre operative Radiograph

an unwanted tipping movement as a result of which the crown of second molars had move distally; creating an open contact between $1^{\text {st }}$ and $2^{\text {nd }}$ molars (figure 2 ). Diagnosis of unwanted orthodontic movement by maxillary $3^{\text {rd }}$ molar leading to proximal open contact between first and second molar was made. The patient was informed of the diagnosis and treatment plan. Both maxillary third molar teeth were extracted within an interval of two weeks under local infiltration anesthesia employing two cartridges of $1.8 \mathrm{ml}$ each of 2\% Xylestesin (Lidocaine) with 1:80,000 epinephrine (3M-ESPE, USA) in each exodontia. Then a waiting period of two months was observed to explore if the second molars would spontaneously drift back to their actual position. However, no change was observed, therefore, an operative management was planned. A class II cavity preparation was made using high and low speed dental drills in the mesial surface of maxillary $2^{\text {nd }}$ molars and distal aspect of the maxillary $1^{\text {st }}$ molars that were later refined with hand

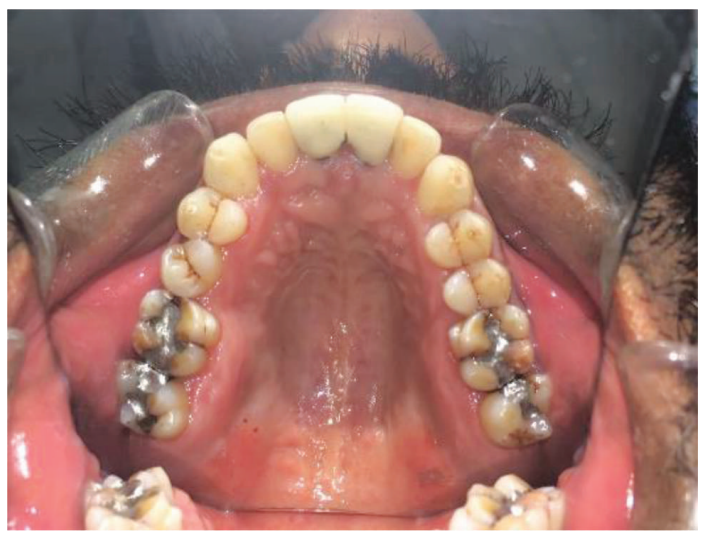

Fig 3. Post op Intra-oral photograph
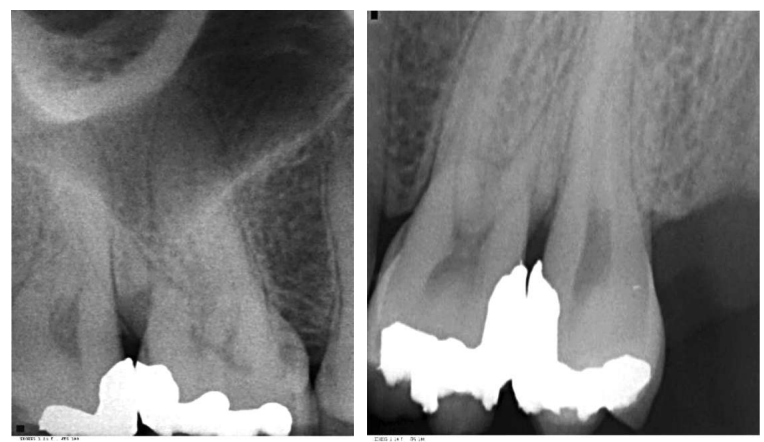

Fig 4a \& b. Post-operative radiograph of right and left sides

instruments. Two circumferential Automatrix bands (Dentsply, USA) were simultaneously placed on the adjacent molars secured with wooden wedges. Admixed particles amalgam restoration (Tytin FC, Kerr Dental, USA) was in the cavity preparations using standard incremental method (figure 3). The patient was kept on regular follow-ups. At one year follow-up, the patient remained asymptomatic. Both the proximal contacts were free of food stagnation and patient could easily pass in the floss with a little physiologic resistance. Figures 4 a \& b show the periapical radiographs at one year follow-up.

\section{DISCUSSION}

Food impaction between teeth is a prevalent clinical condition among all populations. ${ }^{6}$ Food stagnates in the interproximal space, mainly by a vertical plunger effect of the antagonist tooth from the occlusal direction. ${ }^{7}$ Alternatively, food particles also enter in the proximal space from the 
lateral (horizontal) side owing to receded interdental papillae.

In clinical practice, an open proximal contact in absence of caries or periodontal disease is observed when the adjacent marginal ridges heights are uneven and the opposing tooth centric holding cusp plunges the fibrous food particles between the teeth in question. ${ }^{8}$ Food impaction from vertical aspect is mostly iatrogenic in nature caused by an improper Class II restoration or fabrication of a faulty indirect restoration. ${ }^{9}$ In our case, patient's periodontal status was satisfactory and he had no restorations placed in the posterior teeth. After clinical and radiographic investigation, we inferred that the mesio-buccal cusp of the third molars have caused distal tipping movement; creating an open proximal contact between first and second molar. After elimination of the cause of the open contact i.e. the extraction of right and left maxillary third molars, the possible management options were:

1. Keep the open proximal area clean by meticulous flossing

2. Orthodontics to tip back the second molars and resume tight contacts

3. Place direct restorations in one or two teeth

4. Place indirect restorations such as crowns

Flossing cannot be considered as an ultimate treatment option as compliance is a challenge. Orthodontic treatment was not only time consuming but appeared as an overtreatment for a localized problem. Crowns were not preferred as it involved substantial tooth substance cutting and potentially detrimental to vitality of teeth. Therefore, we opted for directly placed Class II amalgam restorations in teeth \# 16, 17 and 26, 27. It was not only cost-effective but time saving with predictable outcome. Amalgam was preferred over composite restorations because it provides tighter proximal contacts with less wear, decreased marginal leakage and extended longevity. ${ }^{10,11}$ The patient was satisfied with the restorations as his food catching problem was predictably resolved in a single visit.

\section{CONFLICT OF INTEREST}

None declared

\section{REFERENCES}

1. Stappert CF, Tarnow DP, Tan JH, Chu SJ. Proximal contact areas of the maxillary anterior dentition. Int J Periodontics Restorative Dent. 2010;30(5):471-7.

2. Jernberg GR, Bakdash MB, Keenan KM. Relationship between proximal tooth open contacts and periodontal disease. J Periodontol. 1983;54(9):529-33.

https://doi.org/10.1902/jop.1983.54.9.529

3. Allison PJ, Schwartz S. Interproximal contact points and proximal caries in posterior primary teeth. Pediatr Dent. 2003;25(4):334-40.

4. Khan FR, Umer F, Rahman M. Comparison of proximal contact and contours of premolars restored with composite restoration using circumferential matrix band with and without separation ring: A randomized clinical trial. Int J Prosthodont Restor Dent. 2013;3(1):7-13.

https://doi.org/10.5005/jp-journals-10019-1068

5. Ventä I, Ylipaavalniemi P, Turtola L. Clinical outcome of third molars in adults followed during 18 years. J Oral Maxillofac Surg. 2004;62(2):182-5.

https://doi.org/10.1016/j.joms.2003.04.011

6. Newell DH, John V, Kim SJ. A technique of occlusal adjustment for food impaction in the presence of tight proximal contacts. Oper Dent. 2002;27(1):95-100.

7. Nagarsekar A, Gaunkar R, Aras M. Knowledge, attitude, and practice of dental professionals regarding the effect and management of food impaction associated with fixed partial denture prostheses:A survey. J Indian Prosthodont Soc. 2016;16(4):372-9.

https://doi.org/10.4103/0972-4052.191286

8. Gokhale S, Padmaja K. Food Impaction after Crown Placements. J Adv Med Dent Scie Res. 2014;2(4):162-5.

9. Khairnar M. Classification of food impaction-revisited and its management. Indian J Dent Adv. 2013; 5(1):11139.

10. El-Badrawy WA, Leung BW, El-Mowafy O, Rubo JH, Rubo MH. Evaluation of proximal contacts of posterior composite restorations with 4 placement techniques. J Can Dent Assoc. 2003;69(3):162-7.

11. Sachdeo A1, Gray GB, Sulieman MA, Jagger DC. Comparison of wear and clinical performance between amalgam, composite and open sandwich restorations: 2year results. Eur J Prosthodont Restor Dent. 2004;12(1):1520. 